\title{
Curva de desidratação e composição químico-bromatológica do feno de grama-estrela (Cynodon nlemfuensis Vanderyst) em função do teor de umidade no enfardamento
}

\section{Dehydratation curve and chemical-bromatologic composition of stargrass (Cynodon nlemfuensis Vanderyst) hay in function of the baling process moisture content}

\author{
Moyses Calixto Junior ${ }^{1}$; Clóves Cabreira Jobim²; Ulysses Cecato²; \\ Geraldo Tadeu Santos²; Valter Harry Bumbieris Junior ${ }^{3 *}$
}

\section{Resumo}

\begin{abstract}
Objetivou-se determinar a curva de desidratação e o efeito do teor de umidade no enfardamento sobre a composição químico-bromatológica do feno de grama-estrela (Cynodon nlemfuensis Vanderyst). Foram realizadas amostragens do momento do corte até o enfardamento, a fim de determinar a curva de desidratação da planta inteira e das frações folha e colmo, com secagem em estufa de ventilação forçada e em forno de microondas. A gramínea foi enfardada com teores de umidade pré-estabelecidos de 25,16 e $12 \%$, em delineamento experimental inteiramente casualizado com dez repetições. A taxa de perda de água foi maior para a fração folha comparada à fração colmo. Houve maior aquecimento para os fenos enfardados com $25 \%$ de umidade nas primeiras horas após a armazenagem. Não houve efeito dos teores de umidade no enfardamento sobre a composição química do feno de grama-estrela, exceto para o teor de proteína bruta e extrato etéreo. A digestibilidade in vitro da matéria seca e da proteína bruta não apresentaram efeito do teor de umidade no enfardamento, com valores médios de 58,73 e $55,42 \%$, respectivamente. O uso de forno de microondas para determinar o teor de umidade da forragem apresentou eficiência semelhante ao método de secagem em estufa com circulação forçada de ar. Nas condições deste estudo os teores de umidade no momento do enfardamento não influenciaram na composição químico-bromatológica do feno de grama-estrela em estádio avançado de desenvolvimento, exceto para o teor de proteína bruta e extrato etéreo.
\end{abstract}

Palavras-chave: Colmo, folha, forragem conservada, microondas, planta inteira

\begin{abstract}
It was aimed at to determine the dehydration curve and the moisture content effect during the baling process in the chemical composition of star grass (Cynodon nlemfuensis Vanderyst) hay. Samples were collected from harvest until baling to determine the dehydration curve of both whole plant and leaf and stem fractions. The baling process occurred with predetermined moisture contents: 25, 16 and $12 \%$. A completely randomized experimental design with ten replications was used, and the chemical bromatological composition data were compared by Tukey Test $(5 \%)$. The water loss rate was higher for leaf when compared to stem fraction. In the early hours after storage, it was noticed higher heat for hays with $25 \%$ of moisture content. There was not effect of moisture content during baling process in
\end{abstract}

\footnotetext{
${ }^{1}$ Zootecnista Dr. Potensal Nutrição Animal, Santo Anastácio, SP. E-mail: m.cjunior@bol.com.br

${ }^{2}$ Profs. Drs. Universidade Estadual de Maringá, UEM, Maringá, PR. Pesquisador Cnpq. E-mail: ccjobim@uem.br; ucecato@uem. br; gtsantos@uem.br

${ }^{3}$ Prof. Dr. do Dept ${ }^{\circ}$ de Zootecnia, Universidade Estadual de Londrina, UEL, Londrina, PR. E-mail: jrbumbieris@uel.br

* Autor para correspondência
} 
the chemical composition of star grass hay, except for crude protein (CP) and ether extract (EE). In vitro dry matter digestibility (INDMD) and in vitro crude protein digestibility (INCPD) were not affected by moisture content in baling process either. It was concluded that the moisture content during the baling process does not affect the chemical composition of star grass hay in advanced stadium of development, except for crude protein and ether extract.

Key words: Conserved forage, leaf, microwave oven, stem, whole plant

\section{Introdução}

O princípio básico da fenação resume-se na conservação do valor nutritivo da forragem por meio da rápida desidratação, uma vez que a atividade respiratória das plantas, bem como dos microrganismos é paralisada. Assim, a qualidade do feno está associada a fatores intrínsecos às plantas que serão fenadas, às condições climáticas ocorrentes durante a secagem e às condições de armazenamento.

O processo de fenação consiste na remoção da umidade da forragem de valores próximos de $80 \%$ para valores abaixo de $20 \%$, permitindo assim o armazenamento do feno com segurança e baixos índices de perdas. Não só o teor de matéria seca no momento do corte, como o tempo de secagem afeta a qualidade do feno produzido (NERES et al., 2010). Em outro estudo, Neres et al. (2011) destacam que a taxa de secagem pode variar de acordo com as características estruturais da forrageira (coastcross, aveia e azevém), especialmente espessura do colmo, razão folha/colmo, interferindo no tempo de secagem e no teor final de matéria seca. $\mathrm{O}$ período de secagem é dividido em três fases, as quais diferem na duração, na taxa de perda de água e na resistência à desidratação (MAcDONALD; CLARK, 1987). Na primeira fase, a secagem é rápida e envolve intensa perda de água, reduzindo a umidade de cerca de $80-85 \%$ para teores próximos de $65-60 \%$, onde a principal perda de água é por transpiração. Na segunda fase, a umidade é reduzida de teores próximos a $60 \%$ para teores ao redor de $30 \%$, sendo a principal perda de água por meio de evaporação cuticular. E na terceira e última fase, a perda de água é favorecida pela plasmólise celular e ocorre redução na umidade de $30-40 \%$ para
$15 \%$ considerado ponto ideal para enfardamento (LAVEZZO; ANDRADE, 1994).

As principais causas de mudanças e perdas no valor nutritivo de fenos durante o armazenamento são devidas ao alto conteúdo de água, que está relacionado com crescimento de microrganismos. A redução no valor nutritivo, primeiramente é devido à atividade microbiológica e posteriormente pelo aquecimento, incluindo oxidação de carboidratos não estruturais (COBLENTZ et al., 1997), ou mesmo complexação de componentes carboidratos com moléculas protéicas.

Coblentz et al. (2000) estudando o efeito do teor de umidade no enfardamento $(32,5 ; 28,7 ; 24,8 ; 20,8$ e $17,8 \%$ ) em feno de grama bermuda, constataram efeito linear decrescente $(\mathrm{P}<0,001)$ para os componentes de FDA e FDN. Houve decréscimo no valor de FDA $(35,8$ para $33,2 \%)$ e FDN $(76,6$ para 70,6\%) comparando-se o maior e menor teor de umidade no momento do enfardamento. Neste mesmo estudo, a DIVMS foi reduzida com o aumento da umidade no enfardamento, com valores de $63,4 \%$ e $50,8 \%$ para os fenos com baixo $(17,8 \%)$ e alto $(32,5 \%)$ teor de umidade.

Verifica-se, portanto que, podem ocorrer alterações na composição químico-bromatológica de fenos quando produzidos com teor de umidade suficiente para permitir atividade de microrganismos. Diante do exposto, objetivou-se com este trabalho determinar a curva de desidratação, em estufa e forno microondas e o efeito do teor de umidade no enfardamento sobre a composição químicobromatológica da planta e das frações colmo e folha do feno de grama-estrela (Cynodon nlemfuensis Vanderyst). 


\section{Material e Métodos}

O experimento foi realizado no período de dezembro de 2003 a janeiro de 2004 na Fazenda Experimental de Iguatemi (FEI), e no Laboratório de Análises de Alimentos e Nutrição Animal (LANA), pertencentes ao Departamento de Zootecnia da Universidade Estadual de Maringá (UEM).
Os dados de temperatura e precipitação, observados durante o período experimental, coletados pelo Posto de Meteorologia da Fazenda Experimental de Iguatemi, são apresentados nas Figuras $1 \mathrm{e} 2$.

Figura 1. Médias de temperaturas máximas e mínimas no período de outubro/2003 a março/2004.

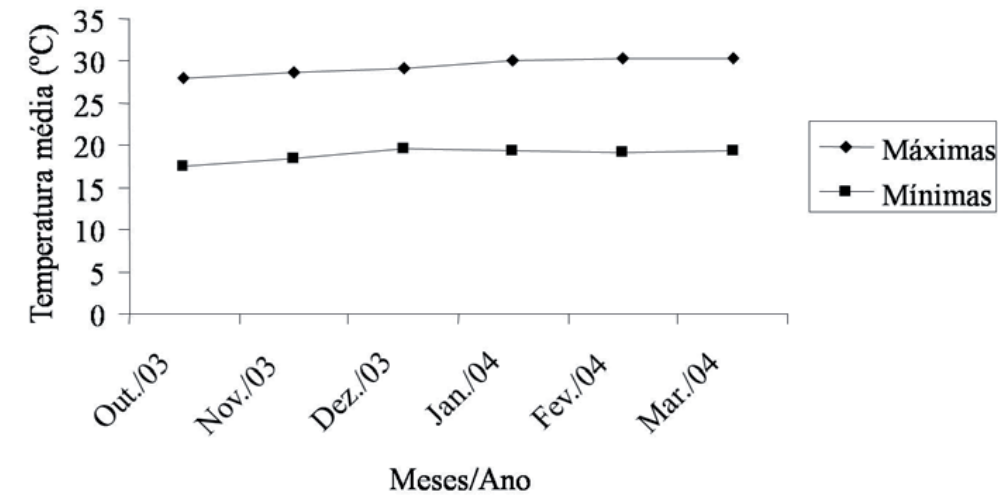

Fonte: Elaboração dos autores.

Figura 2. Precipitação e umidade relativa do ar (URA) registradas no período de outubro/2003 a Março/2004.

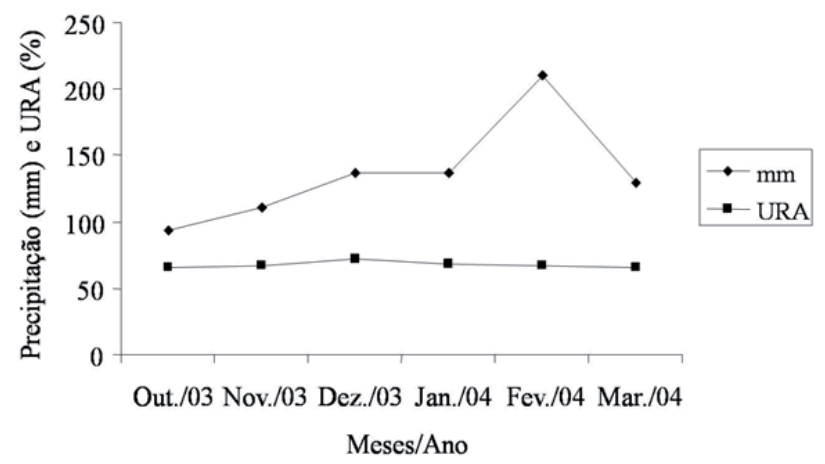

Fonte: Elaboração dos autores.

Os dados referentes às condições climáticas, de Meteorologia da Fazenda Experimental de observadas durante o momento do corte da gramínea Iguatemi, estão apresentado na Tabela 1.

até o enfardamento dos fenos, coletados pelo Posto

Tabela 1. Temperatura média $\left({ }^{\circ} \mathrm{C}\right)$, umidade média $(\%)$, precipitação $(\mathrm{mm})$, insolação $(\mathrm{hs} / \mathrm{sol} / \mathrm{dia})$, nebulosidade (décimos), vento $(\mathrm{m} / \mathrm{s})$, registradas no período de 08/dezembro a 11/dezembro/2003.

\begin{tabular}{ccccccc}
\hline Data & Temperatura & Umidade & Precipitação & Insolação & Nebulosidade & Vento \\
\hline 8 & 25,0 & 77,5 & 0,0 & 5,6 & 9,0 & 1,3 \\
9 & 21,0 & 73,3 & 19,0 & 1,6 & 8,0 & 1,0 \\
10 & 20,0 & 75,2 & 0,0 & 9,2 & 8,3 & 1,0 \\
11 & 22,5 & 85,4 & 0,0 & 4,5 & 8,0 & 1,0 \\
\hline
\end{tabular}

Fonte: Elaboração dos autores. 
Foi utilizada uma área de aproximadamente dois hectares, já estabelecida, com grama-estrela (Cynodon nlemfuensis Vanderyst) a qual se apresentava em estádio vegetativo avançado, com aproximadamente 90 dias de crescimento. O corte da forragem foi efetuado no dia $08 / 12 / 03$ no período da manhã, com a utilização de uma segadora simples de disco. A partir do dia 11/12/03, após atingir o teor de umidade desejada, a forragem foi enfardada com uma enfardadora da marca Nogueira, modelo APN 41, de fardos retangulares com peso médio de $10 \mathrm{~kg}$. A forragem foi enfardada, com teores de umidade pré-estabelecidos de 25, 16 e 12\%. Foram utilizados 10 fardos para cada teor de umidade, totalizando 30 fardos nas avaliações.

Foram realizadas as medidas de temperatura no interior dos fardos no momento do enfardamento e 2, 4, 6, 8, 10 e 12 horas após. Utilizou-se um termômetro digital (modelo GULTERM 1001), com sensor de temperatura o qual foi inserido no interior de cada fardo para o registro das temperaturas.

Foram determinadas as curvas de desidratação para planta inteira e para as frações colmo e folha. Para este procedimento foram realizadas 13 amostragens, sendo uma no tempo zero (no momento do corte) e as outras; 1, 4, 6, 24, 26, 28, $48,52,70,76,77$, e 78 horas após o corte até o momento do enfardamento para cada tratamento (25, 16 e 12\% de umidade). Essas amostras foram pesadas obtendo-se o peso da massa verde, separadas as frações colmo e folha e secas em estufa a $65^{\circ} \mathrm{C}$ por 72 horas para determinação da curva de desidratação da planta e das frações colmo e folha.

Para determinação do teor de MS e a curva de desidratação, foram utilizadas as técnicas de secagem em estufa com circulação de ar a $65^{\circ} \mathrm{C}$ por 72 horas e secagem em forno de microondas (SILVA; QUEIROZ, 2002).

Para análise da composição química, após um período de armazenagem de 60 dias, amostras dos fenos foram coletadas e, posteriormente, moídas em peneira com malha de $1 \mathrm{~mm}$ e encaminhadas ao laboratório, onde foram determinados os teores de matéria seca (MS), proteína bruta $(\mathrm{PB})$, matéria mineral (MM) e extrato etéreo (EE) de acordo com AOAC (1990), fibra em detergente neutro (FDN), fibra em detergente ácido (FDA), e hemicelulose (HCEL), segundo Van Soest e Robertson (1985).

A digestibilidade in vitro da matéria seca (DIVMS) foi determinada pela técnica de dois estádios, de Tilley e Terry (1963). Para a coleta do líquido ruminal foi utilizada uma vaca da raça Holandesa, multípara, seca, com peso vivo médio de $550 \mathrm{Kg}$, munida de fistula ruminal e adaptada a dieta a base de feno de grama-estrela.

Os tratamentos foram arranjados em um delineamento inteiramente casualizado com 10 repetições. Os dados de composição químicobromatológica foram submetidos à análise de variância e de regressão para curvas de desidratação, sendo as médias comparadas pelo teste Tukey (5\%), por meio do Sistema de Análises Estatística (UFV, 1997)

\section{Resultados e Discussão}

A taxa de secagem para a planta inteira e as frações folha e colmo apresentaram comportamento quadrático $(\mathrm{P}<0,05)$, tanto para a secagem com o uso de estufa a $65^{\circ} \mathrm{C}$ por 72 horas como também para o forno de microondas (Figura 3a,b).

A fração folha (Figura 3a, b), apresentou alta taxa de secagem nas primeiras horas após o corte da gramínea, atingindo valores ao redor de $50 \%$ de MS em 4 horas após o corte. A taxa de desidratação das folhas foi semelhante ao observado por Calixto Junior, Jobim e Canto (2007), também em estudo com grama estrela. Verificou-se também que esta fração atingiu 53 e $68 \%$ de MS em 6 e 48 horas após o corte, respectivamente. A fração folha apresentou teor de MS no momento do corte de $48 \%$ e atingiu valor próximo de $80 \%$ de MS em 78 horas após o corte. 
A fração colmo apresentou mais água em relação à fração folha no momento do corte, ou seja, 34\% versus 48\% de MS da fração folha. O colmo apresentou alta taxa de desidratação nas quatro primeiras horas após o corte atingindo valores próximos a 37\% de MS. Nas primeiras 24 horas após o corte o aumento no teor de MS do colmo foi em média de $0,27 \%$ /hora, enquanto que no período de 78 horas a taxa de aumento no teor de MS foi de 0,44\%/hora. No entanto, durante o período de secagem a fração colmo mostrou lenta taxa de perda de umidade, retardando a desidratação da planta. Segundo Calixto Junior, Jobim e Canto (2007) e Neres et al. (2011), a espessura do colmo pode influenciar negativamente na taxa de secagem da gramínea, haja vista que esta fração apresenta maior quantidade de água e menor rapidez na perda de água comparada à fração folha e planta inteira. Estes resultados estão em concordância com Jobim et al. (2001), que trabalhando com cultivares do gênero Cynodon encontraram maior quantidade de água na fração colmo no momento do corte $(30 \%$ MS) e maior taxa de secagem para a fração folha atingindo valores ao redor de $90 \%$ de MS em 24 horas após o corte. $\mathrm{O}$ maior tempo para atingir o teor de MS ideal para o enfardamento, no presente estudo, em relação àquele observado pelos autores, foi devido às condições climáticas desfavoráveis, com tempo nublado e alta umidade relativa do ar (Tabela 1).
A taxa de desidratação da planta inteira mostrou comportamento semelhante às frações colmo e folha, com maior taxa de desidratação nas primeiras horas após o corte. A planta inteira e a fração colmo atingiram valores ao redor de 85 e $79 \%$ de MS (Figura 3b), respectivamente, em 78 horas de secagem a campo. Apesar desse comportamento semelhante, nota-se que a curva de desidratação da planta inteira (PI) foi similar à curva de desidratação da fração colmo em relação à fração folha. Isto pode ser explicado pelo fato da gramínea apresentar-se em estádio vegetativo bastante avançado, com alta participação de colmo na sua composição morfológica, apresentando razão lâmina/colmo de 0,39 .

As curvas de desidratação da planta inteira com secagem em estufa a $65^{\circ} \mathrm{C}$ por 72 horas e com uso de forno de microondas estão apresentadas na Figura 4. Verifica-se que, tanto a determinação da MS pelo método de secagem em estufa como em forno de microondas resultaram em mesmo comportamento para a curva de secagem. No entanto, constatouse que com a secagem em forno de microondas há maior retirada de água da forragem, independente do teor de umidade da amostra. Verificou-se que em média, houve diferença aproximada de nove pontos percentuais em relação à secagem com o uso de estufa a $65^{\circ} \mathrm{C}$ por 72 horas e forno de microondas. 
Figura 3. Curva de desidratação da planta inteira (PI) e das frações colmo e folha da grama-estrela durante a secagem a campo determinada em estufa a $65^{\circ} \mathrm{C}$ por 72 horas (a) e em forno de microondas (b).
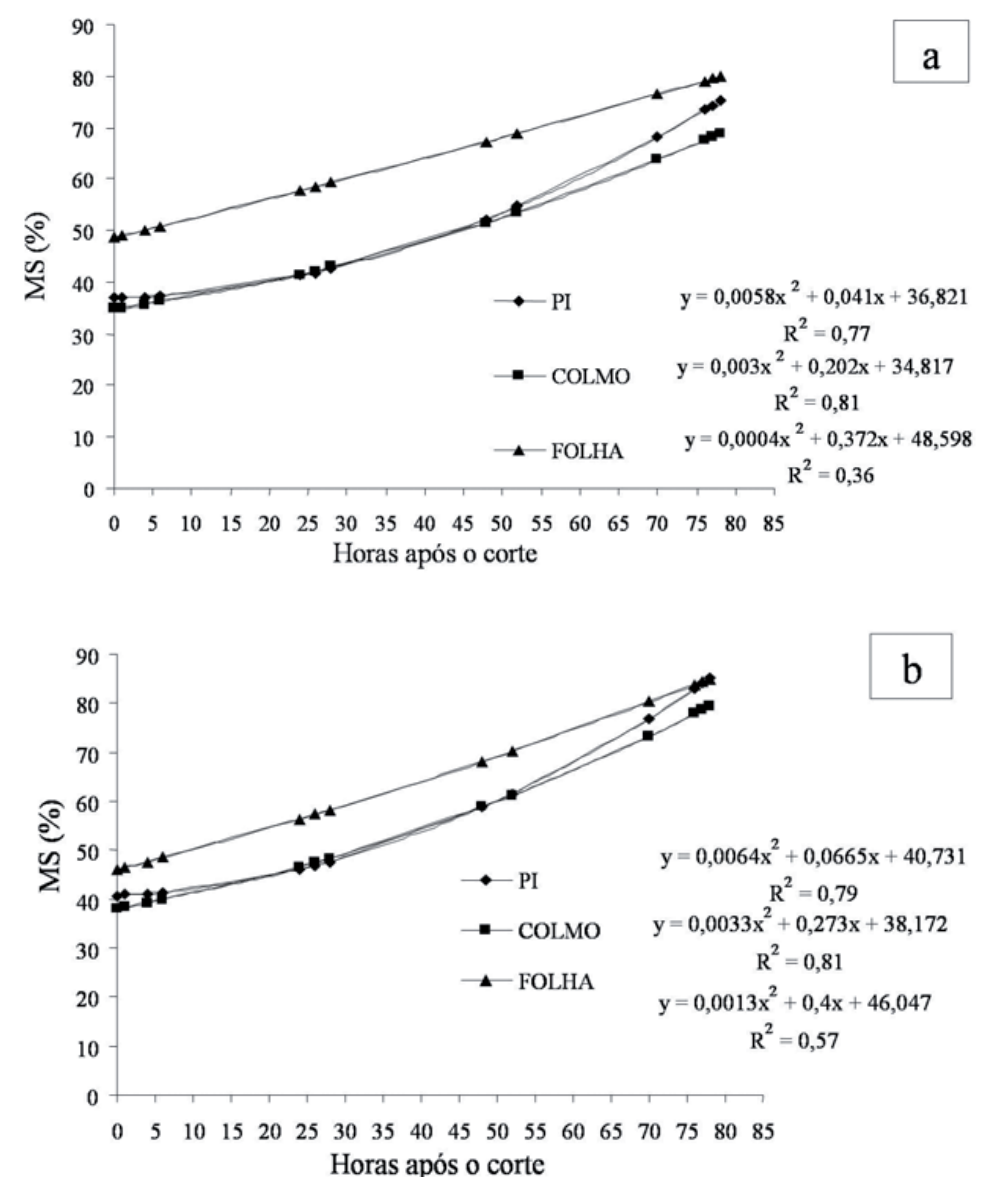

Fonte: Elaboração dos autores.

Figura 4. Curva de desidratação da planta inteira (PI) da grama-estrela durante a secagem a campo determinada em estufa (E) à $65^{\circ} \mathrm{C}$ por 72 horas e forno de microondas (M).

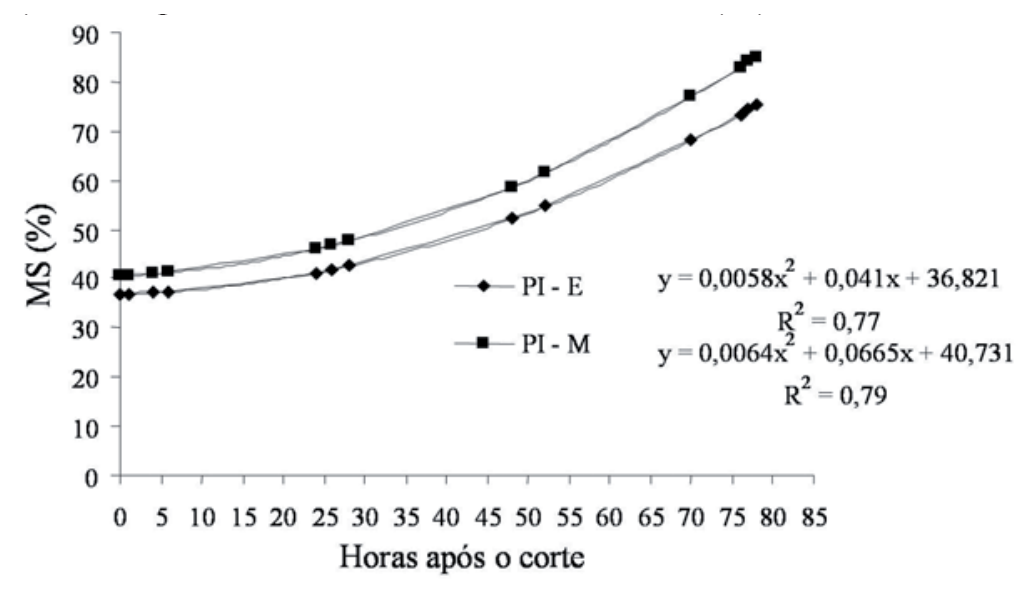

Fonte: Elaboração dos autores. 
A perda de água da fração folha foi muito rápida com curvas bastante semelhantes para os dois métodos de determinação da MS (Figura 5). No início do período de secagem (após 6 horas de secagem no campo), o teor de MS da fração folha com a utilização do forno de microondas foi inferior (49\%) comparado à estufa (52\%). Observa-se que o teor de MS determinado em forno de microondas foi maior ( $86 \%$ de MS) em relação ao determinado em estufa ( $80 \%$ de MS), após 78 horas de secagem a campo.

Figura 5. Curva de desidratação da fração folha da grama-estrela durante a secagem a campo, determinada em estufa (E) a $65^{\circ} \mathrm{C}$ por 72 horas e em forno de microondas (M).

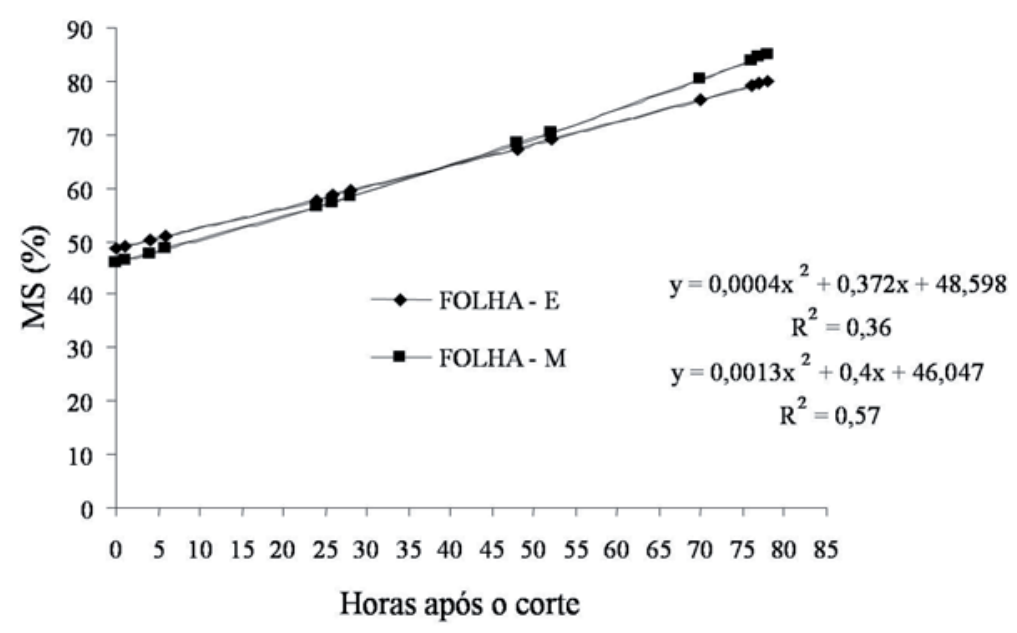

Fonte: Elaboração dos autores.

A fração colmo, independente do método de determinação do teor de MS utilizado, apresentou menor velocidade de secagem (Figura 6). No entanto, no primeiro dia de secagem, após 6 horas do corte da gramínea, constatou-se diferença de 4 pontos percentuais entre os métodos utilizados, sendo que a MS determinada em forno de microondas foi superior ( $40 \%$ de MS) comparada à estufa (36\% de MS).
Após 78 horas de secagem a campo, quando a forragem foi enfardada, observou-se maior diferença (10 unidades percentuais), com valores de $79 \%$ e $69 \%$ de MS para MS determinada em forno de microondas e em estufa, respectivamente. Em média, no período total de secagem a campo, a determinação da MS da fração colmo em forno de microondas foi mais elevada em 7 pontos percentuais em relação à determinação em estufa com circulação de ar. 
Figura 6. Curva de desidratação da fração colmo da grama-estrela durante a secagem a campo determinada em estufa (E) a $65^{\circ} \mathrm{C}$ por 72 horas e forno de microondas (M).

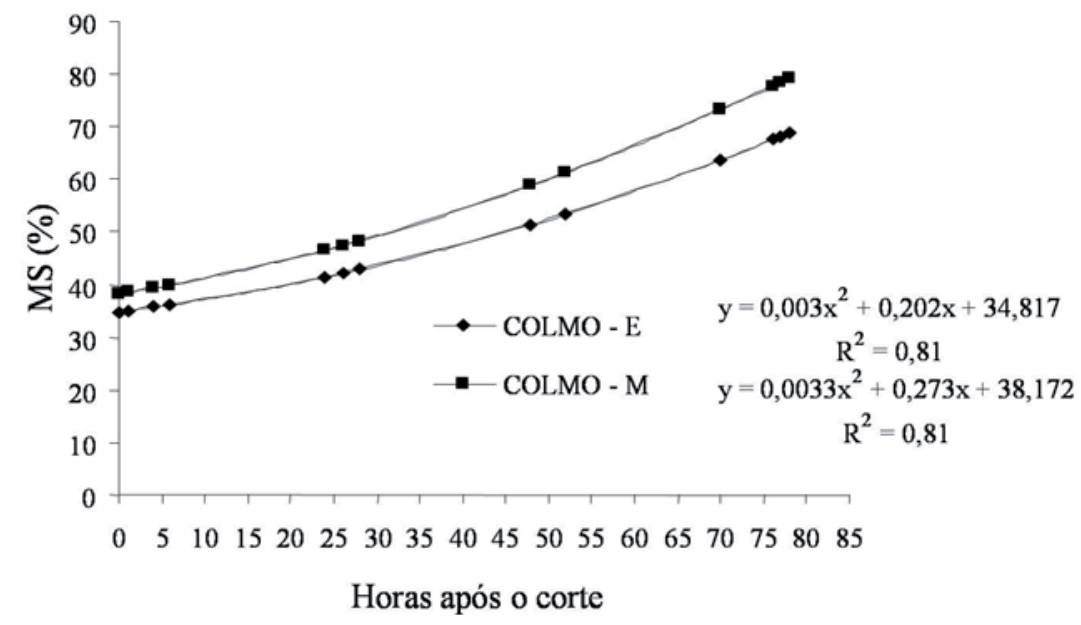

Fonte: Elaboração dos autores.

Verificou-se que as temperaturas dos fenos armazenados com 12 e $16 \%$ de umidade declinaram nas quatro primeiras horas de armazenagem, estabilizando em torno de $26^{\circ} \mathrm{C}$ até o final das avaliações.

O tratamento com $25 \%$ de umidade apresentou aumento inicial da temperatura atingindo valores de $42^{\circ} \mathrm{C}$ nas primeiras 4 horas de armazenagem. Houve uma diminuição na temperatura após 6 horas, estabilizando em torno de $30^{\circ} \mathrm{C}$. Isto pode ser explicado, pela maior atividade microbiológica nos fenos com alta umidade, o que poderia prejudicar a qualidade nutricional dos mesmos.

Aquecimento em fardos armazenados tem sido observado comumente em fenos com umidade acima de $20 \%$. Geralmente, o conteúdo de FDA e FDN aumentam e a digestibilidade da MS diminui com o aquecimento dos fenos (COLLINS et al., 1987; COBLENTZ et al., 1996).

Também Coblentz et al. (1996) encontraram aquecimento de feno nos primeiros 5 dias de armazenagem, valores máximos de 50 e $33^{\circ} \mathrm{C}$ para os fenos com alta umidade $(30 \%)$ e baixa umidade $(20 \%)$ no enfardamento, respectivamente. Neste mesmo trabalho, os autores concluíram que os fenos com alta umidade (30\%) obtiveram extensa atividade microbiológica e conseqüentemente mudança na qualidade do produto final.

Baron e Greer (1988) encontraram temperaturas máximas para os fenos de alfafa de 40,28 e $22^{\circ} \mathrm{C}$ em relação aos fardos com 35, 25 e 15\% de umidade após 10 dias de armazenagem. Temperaturas acima de $65^{\circ} \mathrm{C}$ poderiam ser mais preocupantes, pois reações não enzimáticas poderiam ser facilitadas nessas temperaturas, comprometendo também a qualidade da proteína nestas situações.

$\mathrm{Na}$ Tabela 2 estão apresentados os dados de composição químico-bromatológica do feno de grama-estrela, enfardados nos níveis de 12, 16 e $25 \%$ de umidade e armazenados por 60 dias em galpão. 
Figura 7. Temperatura ambiente (TA) e interna dos fardos durante as 12 horas iniciais de armazenagem para o feno de grama-estrela enfardado com 12,16 e $25 \%$ de umidade.

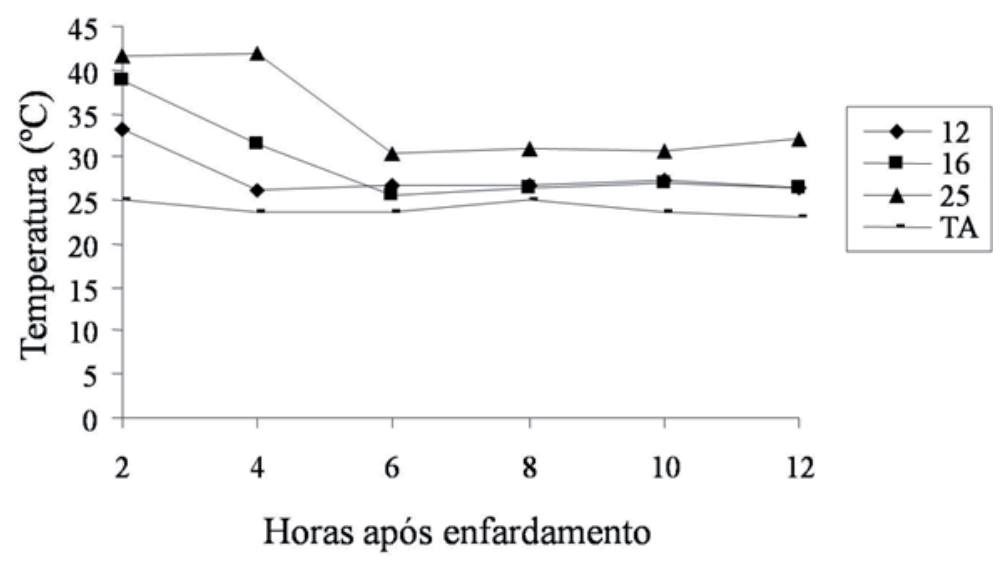

Fonte: Elaboração dos autores.

Tabela 2. Teor médio de proteína bruta (PB), fibra em detergente neutro (FDN), fibra em detergente ácido (FDA), hemicelulose (HCEL), extratro etéreo (EE), matéria mineral (MM), digestibilidade in vitro da matéria seca (DIVMS) e digestibilidade in vitro da proteína bruta (DIVPB), do feno de grama-estrela em função do teor de umidade no enfardamento.

\begin{tabular}{ccccccccc}
\hline $\begin{array}{c}\text { Teor de } \\
\text { Umidade }\end{array}$ & PB & FDN & FDA & HCEL & EE & MM & DIVMS & DIVPB \\
\hline 12 & $6,36 \mathrm{~b}$ & $84,98 \mathrm{a}$ & $44,77 \mathrm{a}$ & $40,21 \mathrm{a}$ & $0,79 \mathrm{a}$ & $4,31 \mathrm{a}$ & $59,47 \mathrm{a}$ & $54,64 \mathrm{a}$ \\
16 & $7,66 \mathrm{ab}$ & $84,11 \mathrm{a}$ & $44,78 \mathrm{a}$ & $39,33 \mathrm{a}$ & $0,56 \mathrm{~b}$ & $4,59 \mathrm{a}$ & $59,11 \mathrm{a}$ & $53,81 \mathrm{a}$ \\
25 & $8,48 \mathrm{a}$ & $85,58 \mathrm{a}$ & $45,74 \mathrm{a}$ & $39,84 \mathrm{a}$ & $0,75 \mathrm{ab}$ & $4,38 \mathrm{a}$ & $57,61 \mathrm{a}$ & $57,81 \mathrm{a}$ \\
\hline $\mathrm{CV} \%$ & 11,74 & 2,53 & 4,69 & 3,81 & 15,77 & 8,6 & 6,01 & 8,98 \\
\hline
\end{tabular}

Médias seguidas de mesma letra nas colunas, não diferem pelo teste Tukey $5 \%$.

Fonte: Elaboração dos autores.

Em relação a variável $\mathrm{PB}$, o feno com $25 \%$ de umidade mostrou-se superior $(\mathrm{P}<0,05)$ comparado ao tratamento com $12 \%$ de umidade no enfardamento. Embora a PB possa sofrer degradação microbiológica, é bem menos susceptível a perdas por respiração comparada aos outros nutrientes (BARON; MATHISON, 1990). A concentração de PB pode ter aumentado em termos proporcionais, uma vez que os resultados são expressos em percentagem, tendo em vista ter ocorrido queima por respiração de carboidratos não estruturais. Os teores de PB observados evidenciam que a gramaestrela em estádios avançados apresenta deficiência deste nutriente, comprometendo sua qualidade.
Não houve diferença para o componente FDN em relação aos tratamentos estudados, atingindo valor médio de $84,9 \%$. Estes dados discordam de Coblentz et al. (2000) que verificaram aumento no teor de FDN de 70,6\% para 76,6\% em relação ao menor nível de umidade $(17,8 \%)$ e maior nível $(32,5 \%)$ no momento do enfardamento, em trabalho realizado com feno de grama-bermuda.

Em relação à fração FDA, não houve diferença entre os tratamentos estudados, com valor médio de $45,1 \%$ na MS. Dados de literatura evidenciam o que teor de FDA não apresenta comportamento definido em função do teor de umidade no enfardamento. Neste contexto, Coblentz et al. (2000), em trabalho 
com grama bermuda, encontraram efeito linear $(\mathrm{P}<0,001)$ para teor de umidade $(17,8$ e $32,5 \%)$ no enfardamento, atingindo valores de FDA próximos de 31,8 e 35,8\%. Já Turner et al. (2003) observaram redução na concentração de FDA de 43,4 para $39,7 \%$ em feno de festuca enfardado com baixa umidade $(9,9 \%)$ e alta umidade $(22,4 \%)$. Os valores médios de FDN $(84,9 \%)$ e FDA $(45,1 \%)$ no presente trabalho são considerados elevados, e isto é devido ao estádio avançado da gramínea no momento do corte, mostrando que houve aumento das frações fibra e conseqüentemente podendo ter ocasionado diminuição nos teores de carboidratos solúveis.

Segundo Rotz e Muck (1994), o aumento na concentração de compostos fibrosos dos fenos é devido à atividade de microorganismos, principalmente nos fenos com alto teor de umidade, ocasionando oxidação de carboidratos não estruturais.

As concentrações de hemicelulose não mostraram diferença, atingindo valor médio de 40,1\% para os tratamentos com 12,16 e $25 \%$ de umidade no enfardamento. A pequena variação observada para o teor de hemicelulose deve-se aos valores obtidos para as frações FDN e FDA, uma vez que a mesma foi calculada por diferença.

Os teores de EE mostraram diferença para o tratamento com $16 \%$ de umidade no enfardamento em relação ao tratamento com $12 \%$ de umidade. Não há explicação lógica para o resultado observado, podendo ser atribuído efeito de diluição em relação ao outros componentes expressos na MS ou mesmo à variabilidade de amostras (CV 15,77\%). De acordo com Church (1988), a grande maioria das forrageiras apresenta pequena quantidade de extrato etéreo em sua constituição, podendo alcançar até $3,5 \%$ na MS, sendo esse um fator positivo uma vez que os bovinos são tolerantes até níveis de 7,0\% na MS na dieta total.

Também para as concentrações de MM, não houve diferença significativa entre os tratamentos estudados, com valor médio de 4,43\% na MS.
A DIVMS não apresentou diferença para os tratamentos estudados. Nesse sentido, Coblentz et al. (2000), encontraram valores de digestibilidade de 50,8 e $61,7 \%$ em fenos com 32,8 e $24,8 \%$ de umidade. Estes autores observaram aquecimento nos fardos com alta umidade mostrando ter ocorrido alta atividade dos microrganismos e, conseqüentemente, oxidação dos carboidratos não estruturais que são de alta digestibilidade.

Fenos enfardados com umidade abaixo de $20 \%$ não sofrem danos em relação ao valor nutritivo podendo assim ser armazenados com total segurança (COLLINS et al., 1987). Aumento de 59,8 para $63,2 \%$ na digestibilidade em fenos armazenados com alto e baixo nível de umidade (22,4 e 9,9\%) foi observado por Turner et al. (2003). Estes autores, explicam que a diferença na digestibilidade é devido à melhor conservação dos carboidratos não estruturais pelos fenos armazenados com baixa umidade.

Não houve diferença em relação a DIVPB, com valor médio de $55,42 \%( \pm 2,39)$, o que pode ser atribuído ao fato das perdas de compostos nitrogenados serem menores que as de carboidratos solúveis e a digestibilidade da proteína bruta, só será grandemente afetada com aumento na temperatura e/ou alta interferência de microrganismos (REIS et al., 2001).

\section{Conclusão}

O uso de forno de microondas para determinar o teor de umidade da forragem apresenta eficiência semelhante ao método de secagem em estufa com circulação forçada de ar, porém constatou-se que com a secagem em microondas há maior retirada de água da forragem, independente do teor de umidade da amostra.

Para a grama-estrela, a fração folha apresenta maior taxa de perda de água em relação ao colmo.

Os teores de umidade de 12,16 e $25 \%$ no momento do enfardamento não influenciaram na 
composição químico-bromatológica do feno de grama-estrela, possibilitando o enfardamento com teores de até $25 \%$ de umidade.

\section{Referências}

ASSOCIATION OF OFFICIAL ANALYTICAL CHEMISTS - AOAC. Official methods of analysis. 15. ed. Arlington: AOAC International, 1990.

BARON, V. S.; GREER, G. G. Comparison of six commercial hay preservatives under simulated storage conditions. Canadian Journal of Animal Science, Sherbrooke, v. 68, p. 1195-1207, 1988.

BARON, V. S.; MATHISON, G. W. Yield, quality and preservation of moist hay subjected to rain-free and wathered conditions. Canadian Journal of Animal Science, Sherbrooke, v. 70, n. 2, p. 611-622, 1990.

CALIXTO JUNIOR, M.; JOBIM, C. C.; CANTO, M. W. Taxa de desidratação e composição químicobromatológica do feno de grama-estrela (Cynodon nlemfuensis Vanderyst) em função de níveis de adubação nitrogenada. Semina: Ciências Agrárias, Londrina, v. 28, n. 3, p. 493-502, 2007.

$\mathrm{CHURCH}, \mathrm{D}$. C. The ruminant animal: digestive physiology and nutrition. Engleword Cliffs: OeB Broks, 1988.

COBLENTZ, W. K.; FRITZ, J. O.; BOLSEN, K. K.; COCHAN, R. C. Quality changes in alfalfa hay during storage in bales. Journal of Dairy Science, Savoy, v. 79, n. 5, p. $873-885,1996$.

COBLENTZ, W. K.; FRITZ, J. O.; BOLSEN, K. K.; COCHRAN, R. C.; FU, L. Q. Relating sugar fluxes over time to quality changes in alfalfa hay. Agronomy Journal, Madison, v. 89, n. 5, p. 800-806, 1997.

COBLENTZ, W. K.; TURNER, J. E.; SCARBROUGH, D. A.; LESMEISTER, K. E.; JOHNSON, Z. B.; KELLOG, D. W.; COFFEY, K. P.; McBETH, L. J.; WEYERSV, J. S. Storage characteristics and nutritive value changes in bermudagrass hay as affected by moisture content and density of rectangular bales. Crop Science, Madison, v. 40, n. 5, p. 1375-1383, 2000.

COLLINS, M.; PAULSON, W. H.; FINNER, M. F.; JORGENSEN, N. A.; KEULER, C. R. Moisture and storage effects on dry matter and quality losses of alfalfa in round bales. Transactions of the ASAE. American Society of Agricultural Engineers, Beltsville, v. 30, n. 4, p. 913-917, 1987.
JOBIM, C. C.; LOMBARDI, L.; GONÇALVES, G. D.; CECATO, U.; SANTOS, G. T.; CANTO, M. W. Desidratação de cultivares de Cynodon spp. durante o processo de fenação. Acta Scientiarum, Maringá, v. 23, n. 4, p. 795-799, 2001.

LAVEZZO, W.; ANDRADE, J. B. Conservação de forragens: Feno e Silagem. In: SIMPÓSIO BRASILEIRO DE FORRAGICULTURA E PASTAGENS, 1., 1994, Campinas. Anais... Campinas: Colégio Brasileiro de Nutrição Animal, 1994. p. 105-106.

MAcDONALD, A. D.; CLARK, E. A. Water and quality loss during field drying of hay. Advances in Agronomy, Newark, v. 41, p. 407-437, 1987.

NERES, M. A.; CASTAGNARA, D. D.; MESQUITA, E. E.; JOBIM, C. C.; TRÊS, T. T.; OLIVEIRA, P. S. R.; OLIVEIRA, A. A. M. Production of tifton 85 hay overseeded with White oats or ryegrass. Revista Brasileira de Zootecnia, Viçosa, MG, v. 40, n. 8, p. 16381644-2011.

NERES, M. A.; CASTAGNARA, D. D.; MESQUITA, E. E.; ZAMBOM, M. A.; SOUZA, L. C.; OLIVEIRA, P. S. R.; JOBIM, C. C. Production of alfafa hay under different drying methods. Revista Brasileira de Zootecnia, Viçosa, MG, v. 39, n. 8, p. 1676-1683-2010.

REIS, R. A.; MOREIRA, A. L.; MÁRCIO, S. P. Técnicas para produção e conservação de fenos de forrageiras de alta qualidade. In: SIMPÓSIO SOBRE PRODUÇÃO E UTILIZAÇÃO DE FORRAGENS CONSERVADAS, 1. 2001, Maringá. Anais... Maringá: [s.n], 2001. p. 1-39.

ROTZ, C. A.; MUCK, R. E. Changes in forage quality during harvest and storage. In: NATIONAL CONFERENCE ON FORAGE QUALITY, EVALUATION, AND UTILIZATION, 1994, Lincoln. Proceedings... Lincoln: University of Nebraska, 1994. p. 828-868.

SILVA, D. J.; QUEIROZ, A. C. Análise de alimentos: métodos químicos e biológicos. Viçosa: UFV, 2002.

TILLEY, J. M. A.; TERRY, R. A. A two stages technique for the "in vitro" digestion of forages crops. Journal of the British Grassland Society, Oxford, v. 18, n. 1, p. 104111, 1963.

TURNER, J. E.; COBLENTZ, W. K.; SCARBROUGH, D. A.; RHEIN, R. T.; COFFEY, K. P.; RODENKRANS JUNIOR, C. F.; KELLOG, D. W.; SKINNER JUNIOR, J. $\mathrm{V}$. Changes in nutritive value of tall fescue hay as affected by natural rainfall and moisture concentration at baling. Animal Feed Science and Technology, Amsterdam, v. 109, n. 1-4, p. 47-63, 2003. 
UNIVERSIDADE FEDERAL DE VIÇOSA - UFV. SAEG. Sistema para análises estatísticas e genéticas. Versão 7.1.Viçosa: Editora UFV, 1997. (Manual do usuário).

VAN SOEST, P. J.; ROBERTSON, J. B. Analysis of forages and fibrous foods: a laboratory manual for animal science. Ithaca: Cornell University, 1985. 